\title{
Quantitative genetics of the dung fly Sepsis cynipsea: Cheverud's conjecture revisited
}

\author{
THOMAS REUSCH \& WOLF U. BLANCKENHORN* \\ Zoological Museum, University of Zürich, Winterthurerstrasse 190, CH-8057 Zürich, Switzerland
}

\begin{abstract}
Full-sib heritabilities, phenotypic and genetic correlations of 10 morphological and three life history traits in the European dung fly Sepsis cynipsea are presented. We further supply a within-species test of Cheverud's (1988) conjecture that phenotypic correlations may be good, and much easier to obtain, substitutes for genetic correlations. Males were smaller in all traits except fore femur width. Heritabilities of morphological traits ranged from 0.33 to 0.90 and tended to be higher than the average reported for ectotherms (Mousseau \& Roff, 1987). Those for the three female life history traits estimated were lower (0.16-0.32) and about average. Genetic correlations between the sexes ranged from 0.52 to 0.87 and were all less than unity. Differential selection on morphology in males and females can thus be expected to produce fast evolutionary responses in this species. Our analysis revealed also that in S. cynipsea phenotypic correlations are good substitutes for genetic correlations for combinations involving morphological traits, and that genetic correlations derived from the ANCOVA and the family mean methods were very similar. However, the former correspondence may be strongly reduced by the inclusion of particular traits (here male seta length).
\end{abstract}

Keywords: genetic correlation, heritability, life history, morphology, phenotypic correlation, sexual size dimorphism.

\section{Introduction}

The evolutionary analysis of quantitative traits depends on estimation of two central genetic parameters, the heritability and the genetic correlation (Roff, 1995, 1996, 1997). In combination with modern quantitative measurements of selection, estimates of these parameters permit prediction of the evolutionary response of one or more traits to selection (Lande \& Arnold, 1983; Arnold \& Wade, 1984). For this purpose estimates from natural populations would be most desirable, but these are often difficult to obtain. Therefore, laboratory estimates must suffice in many cases; fortunately, contrary to conventional wisdom, these are not overly inflated (Simons \& Roff, 1994, 1996; Weigensberg \& Roff, 1996).

Even laboratory estimation of quantitative genetic parameters is labour intensive and time-consuming. This is particularly true for genetic correlations between two traits, which unless sample sizes are extremely large tend to have wide confidence intervals (Roff, 1995). Analysing data from 23 published

\footnotetext{
*Correspondence. E-mail: wolfman@zoolmus.unizh.ch
}

studies, Cheverud (1988) conjectured and showed that phenotypic (Pearson product-moment) correlations can be good, and much easier to obtain, substitutes for genetic correlations (see also Roff \& Mousseau, 1987 for similar data). Willis et al. (1991) subsequently criticized Cheverud's (1988) methods of analysis and the fact that most data stemmed from laboratory studies of morphological traits, which may not be representative. Since then, two similar studies using more refined methods and more extensive datasets have appeared (Koots \& Gibson, 1996; Roff, 1996). In addition, there are now some single-species studies specifically addressing Cheverud's conjecture: Hughes (1995) on Drosophila melanogaster; Roff (1995) on Gryllus firmus; Simons \& Roff (1996) on Gryllus pennsylvanicus; Tucic \& Avramov (1996) on Iris pumila; and Bonnin et al. (1997) on Medicago trunculata. With the exception of Hughes (1995), all these studies support Cheverud's conjecture, but the issue remains contentious (Willis et al., 1991; Roff, 1996, 1997).

The purpose of this paper is twofold. First, we present phenotypic values, full-sib heritabilities of and the phenotypic and genetic correlations among 10 morphological and three (female) life history 
traits for the dung fly $S$. cynipsea, the most common and abundant European species of a large group of similar-looking, ant-like dung flies of the family Sepsidae (Pont, 1979; Meier, 1996). As part of a larger research programme on the evolution of sexual size dimorphism in dung flies, estimates of these parameters are necessary to evaluate the effects of selection on body size evolution. Body size continues to be one of the most prominent quantitative traits under evolutionary scrutiny because of its strong relationship with many physiological and fitness characters (Peters, 1983; Schmidt-Nielsen, 1984; Roff, 1992), and because of conspicuous general evolutionary patterns of sexual size dimorphism and body size allometry in many organisms (Lande, 1980; Fairbairn \& Preziosi, 1994; Jablonski, 1997). The second purpose of this paper is to supply another extensive dataset testing Cheverud's (1988) conjecture within a species, as was called for by Roff (1995).

\section{Materials and methods}

\section{Rearing procedures}

The individuals used in this study stemmed from the fourth laboratory generation of a S. cynipsea population in Fehraltorf near Zurich $\left(47^{\circ} 23^{\prime} \mathrm{N}, 8^{\circ} 44^{\prime} \mathrm{E}\right)$ collected in September 1994. In the laboratory the flies were held in six 3.5-L plastic group-rearing containers, where they had continuous, ad libitum access to sugar and pollen (for food), water, and fresh dung (for food and oviposition). They were kept in a climate chamber at $27-30^{\circ} \mathrm{C}$ (range), $\approx 40 \%$ relative humidity, and $15 \mathrm{~h}$ photoperiod. A description of the general rearing procedures can be found in Blanckenhorn et al. (1998).

As soon as they eclosed as adults in the large rearing containers, the (third-generation) individuals serving as parents in this study were separated according to sex. Pairs were then randomly assembled into $100 \mathrm{~mL}$ glass bottles containing the above nutrients in miniature plastic dishes, which were capped with a paper stopper. Males and females originated from different rearing containers to avoid brother-sister matings. The pairs stayed together in these bottles until the females had produced three clutches of eggs, and thereafter they were discarded. Each of the three full-sib clutches per family was raised in $50-\mathrm{mL}$ plastic containers capped with toilet paper lids containing a superabundant ( $>1 \mathrm{~g}$ per larva) amount of dung (Blanckenhorn et al., 1998). Only one of these offspring sibships per family was considered for the experi- ment; the others served as back-ups and were later discarded. There was a total of 38 full-sib families for which offspring data were collected. Contrary to the parents, which developed in Petri dishes containing many conspecific larvae of various parents (i.e. at relatively high larval densities), the offspring generation developed under little to no larval competition. Therefore, parent-offspring regression could not be performed.

As soon as the individuals of the offspring generation eclosed in their individual rearing containers, they were again separated by sex. From one of the three containers (corresponding to the three clutches) per family that yielded at least 10 male and 10 female offspring, pairs were again assembled, such that the 10 (randomly picked) males of a particular family were paired with the 10 (randomly picked) females of another family selected at random, and vice versa. As for the parents, they were left until the females of each offspring pair had produced three clutches of eggs; thereafter the individuals were frozen for later measurement.

\section{Traits measured}

For all the 38 families of 10 female and 10 male offspring, several individual life history and morphological traits were measured. The number of eggs in each clutch was counted, and an estimate was made of the egg volume of the ellipsoid eggs as the mean of five randomly picked eggs from the first clutch of each female as (4/3) $\pi$ (egg length/2) (egg width/2) Because S. cynipsea females sometimes lay incomplete clutches, fecundity was additionally expressed as eggs laid per day. Eggs per day was calculated for each female as the total number of eggs laid divided by the time period spanning the first and the last oviposition [i.e. eggs per day (all days)]; alternatively, eggs per day was calculated with respect to the time period from the fourth to the tenth day of a female's adult life [i.e. eggs per day (days 4-10)]. Unless specified, the former measure was used in all analyses. Development time was not considered because of too little variation at high temperatures when checked on a daily basis (Blanckenhorn, 1997).

Ten morphological traits (depicted in Blanckenhorn et al., 1998) were measured: head width, thorax length and width, wing length and width (left and right), hind tibia length (left and right), fore tibia length (left and right), fore femur length and width (left and right), and the length of the longest male fore femoral setae or spines (left and right), part of the claspers with which males hold on to the females' wing bases (Pont, 1979). All measurements 
were performed with a binocular microscope at $40 \times$ magnification (to the nearest $1 / 80 \mathrm{~mm}$ ).

For a subset of 20 males and 20 females, all morphological variables were measured five times at daily intervals to estimate measurement error and the repeatability of the measurements (Falconer, 1989; Becker, 1992).

\section{Statistical analysis}

Repeatabilities $R$ and full-sib heritabilities $h^{2}$ were calculated using standard ANOVA approaches (Falconer, 1989; Becker, 1992; Roff, 1997).

$$
\begin{aligned}
R & =V_{\text {aInd }} /\left(V_{\text {aInd }}+V_{\text {wInd }}\right) \\
& =\left(M S_{\text {aInd }}-M S_{\text {wInd }}\right) /\left[M S_{\text {aInd }}+(m-1) M S_{\text {wInd }}\right],
\end{aligned}
$$

where $V_{\text {and }}$ and $V_{\text {wInd }}$ are the among- and withinindividual variance components, $M S_{\text {aInd }}$ and $M S_{\text {wInd }}$ the corresponding mean squares from the ANOVA, and $m$ is the number of measurements per individual.

$$
\begin{aligned}
h^{2} & =2 V_{\mathrm{aFam}} /\left(V_{\mathrm{aFam}}+V_{\mathrm{wFam}}\right) \\
& =2\left(M S_{\mathrm{aFam}}-M S_{\mathrm{wFam}}\right) /\left[M S_{\mathrm{aFam}}+(k-1) M S_{\mathrm{wFam}}\right],
\end{aligned}
$$

where $V_{\mathrm{aFam}}$ and $V_{\mathrm{wFam}}$ are the among- and withinfamily variance components, $M S_{\text {aFam }}$ and $M S_{\text {wFam }}$ the corresponding mean squares from the ANOVA, and $k$ is the weighted mean family size (unequal because of missing values). Approximate standard errors of both $R$ and $h^{2}$ were estimated as in Becker (1992) and Roff (1997). For the paired traits, the mean of the left and right measurements was used for analysis, but $h^{2}$ was additionally calculated for the individual measurements for comparison. The genetic and residual (environmental) coefficients of variation standardized by the trait mean were also computed (Houle, 1992):

$$
C V_{\mathrm{aFam}}=100\left[\sqrt{ }\left(V_{\mathrm{aFam}}\right) / \text { trait mean }\right]
$$

and

$$
C V_{\mathrm{Res}}=100\left[\sqrt{ }\left(V_{\mathrm{wFam}}\right) / \text { trait mean }\right] \text {. }
$$

The genetic correlations between the sexes were calculated using two methods, the variance component method and the family mean method. The variance component method considers the character as expressed in two environments, the 'environment' here being sex (Yamada, 1962; Fry, 1992; Roff, 1997):

$r_{\mathrm{g}(\mathrm{sex})}=\frac{\operatorname{COV}\left(M_{\mathrm{Fj}}, M_{\mathrm{M} j}\right)}{\sqrt{V\left(M_{\mathrm{F} j}\right) V\left(M_{\mathrm{M} j}\right)}}=\frac{\left(M S_{\mathrm{aFam}}-M S_{\mathrm{Fam} \times \mathrm{Sex}}\right)}{\left(k_{\mathrm{F}}+k_{\mathrm{M}}\right) \sqrt{V\left(M_{\mathrm{F} j}\right) V\left(M_{\mathrm{M} j}\right)}}$, where $\operatorname{COV}\left(M_{\mathrm{F} j}, M_{\mathrm{M} j}\right)$ refers to the covariance in the trait $j$ as expressed in females (F) and males (M). These are estimated from two-way ANOvas with $M S_{\text {aFam }}$ and $M S_{\text {Fam } \times \text { Sex }}$ as the among-family and family-by-sex mean squares, and $k_{\mathrm{F}}$ and $k_{\mathrm{M}}$ as family sizes for females and males. The corresponding single-sex variances $V\left(M_{\mathrm{Fj}}\right)$ and $V\left(M_{\mathrm{M}_{j}}\right)$ are the among-family variance components $V_{\mathrm{aFam}}$ as above, best estimated from separate one-way ANovas. $F=\left(M S_{\text {aFam }} / M S_{\text {Fam } \times \text { Sex }}\right)$ serves as an approximate test of whether $r_{\mathrm{g}(\mathrm{sex})}$ differs significantly from zero, but no such test for significant deviations from unity exists. Therefore, an approximate standard error for each correlation was estimated using a deleteone-family jack-knife described in Roff \& Preziosi (1994), with which a one-sample $t$-test could then be performed. The family mean method simply computes $r_{\mathrm{m}(\mathrm{sex})}$ as the phenotypic (productmoment) correlation between the family trait means as expressed in both sexes (Simons \& Roff, 1996; Roff, 1997). The corresponding standard error is:

$\mathrm{SE}\left(\mathrm{r}_{\mathrm{m}(\mathrm{sex})}\right)=\sqrt{ }\left[\left(1-r_{\mathrm{m}(\mathrm{sex})}^{2}\right) /(n-2)\right]$,

where $n$ is the number of families. One-sample $t$-tests can then be used to test for deviations from zero and unity.

In analysing the genetic $\left(r_{\mathrm{g}}\right)$ and phenotypic $\left(r_{\mathrm{p}}\right)$ correlations within individuals, the methods of Roff (1995, 1996) were closely followed.

$r_{\mathrm{g}}=C O V(X, Y)_{\mathrm{aFam}} / \sqrt{ }\left[V(X)_{\mathrm{aFam}} V(Y)_{\mathrm{aFam}}\right]$

can be computed from ANCOVAs analogous to those for $h^{2}$ (Becker, 1992; Roff, 1997), with:

$\mathrm{SE}\left(r_{\mathrm{g}}\right)=\left(1-r_{\mathrm{g}}^{2}\right) \sqrt{ }\left\{8 /\left[N \sqrt{ }\left(h_{X}^{2} h_{Y}^{2}\right)\right]\right\}$

as its approximate standard error (Roff, 1995), which is a function of the total number of individuals $N$ and the heritabilities of the two traits $X$ and $Y$. The phenotypic correlation $r_{\mathrm{p}}$ is simply the Pearson product-moment correlation using all individuals $N$, with the standard error as above. The genetic correlation can further be approximated as the Pearson product-moment correlation among the family trait means $r_{\mathrm{m}}$ (Via, 1984; Roff, 1997). To examine the correspondence between these measures, $r_{\mathrm{g}}$ was regressed on $r_{\mathrm{p}}$ as well as on $r_{\mathrm{m}}$. The assumptions of linear regression were clearly violated by the data but the primary interest was in the estimates of slope and intercept rather than the significance of the relationship (see discussion in Roff, 1995, 1996). The significance of the correspondence was therefore assessed using a Mantel test (Cheverud, 1988; Roff, 1995). The mean 
absolute difference is also reported between $r_{\mathrm{g}}$ and $r_{\mathrm{p}}$ and between $r_{\mathrm{g}}$ and $r_{\mathrm{m}}$,

$D_{\mathrm{abs}}=\frac{\sum\left|r_{\mathrm{g}, i j}-r_{\mathrm{p}, i j}\right|}{n}$ and $D_{\mathrm{abs}}=\frac{\sum\left|r_{\mathrm{g}, i j}-r_{\mathrm{m}, i j}\right|}{n}$,

where $i, j$ refer to traits $i$ and $j(i \neq j)$ and $n$ is the total number of pairs of correlations (Roff, 1995).

\section{Results}

Phenotypic values, heritabilities and repeatabilities

Repeatabilities for males and females differed in no case (all $t_{19}<1.4, P>0.2$ ), so the combined analysis for all 40 individuals is presented (Table 1). When measuring the same trait of the same individual five times, measurement error was typically very low, except for the smallest traits, fore femur width and seta length (males only).

All mean trait values differed between males and females (all $t_{37}>10, P<0.001$ ), males being generally smaller except in fore femur width. Heritabilities were consequently calculated separately for each sex. Full-sib heritabilities for all morphological traits (except female fore femur width) were high, whereas those for the three female life history traits estimated were lower (Table 1). All $h^{2}$ differ significantly from zero at $P<0.001$, as indicated by the ANOVA $F$-tests, except for eggs per day, which is significant only at $P=0.01$. As the degree of imbalance in the dataset can be considered minor (see $k$ in Table 1), the approximate SEs given should be satisfactory (cf. Simons \& Roff, 1994; Roff, 1997). The individual $h^{2}$ estimates differed between the sexes only for fore femur width (paired $t_{37}=2.11$, $P=0.041$ ), but even this is not significant when employing the sequential Bonferroni correction for nine comparisons. Heritabilities of the seven paired traits were only slightly inflated by analysing the mean of left and right measurements, which of course reduced error: $h^{2}$ for the individual measurements were only $0.4-3.5 \%$ lower, except for fore femur width and seta length (males only), for which the reduction was more substantial (15.2-18\%; compare Table 1).

Mean-standardized coefficients of full-sib genetic and residual variation for the nine morphological traits (seta length excluded for direct comparison) averaged $C V_{\mathrm{aFam}}=2.40 \%(\mathrm{SE}=0.28)$ and $C V_{\mathrm{Res}}=$ $3.42 \%(0.82)$ for males and $C V_{\mathrm{aFam}}=3.06 \%(0.31)$ and $C V_{\text {Res }}=3.77 \%(0.41)$ for females (Houle, 1992). The average $C V_{\mathrm{aFam}}$ was higher for males than for females $\left(t_{8}=4.80, P=0.0014\right)$, whereas the $C V_{\text {Res }}$ did not differ between the sexes $\left(t_{8}=1.14\right.$, $P=0.287)$. For the three female life history traits clutch size, eggs per day and egg volume, the $C V_{\mathrm{aFam}}$ were $7.21 \%, 12.32 \%$ and $2.07 \%$ and the $C V_{\text {Res }}$ $16.56 \%, 41.23 \%$ and $5.24 \%$, respectively.

\section{Genetic correlations between the sexes}

For all nine morphological traits expressed in both sexes, two-way ANOvas indicated differences between the sexes $\left(F_{1,660} \geq 279.15\right)$, genetic variation among families $\left(F_{37,37} \geq 2.86\right)$ and an interaction $\left(F_{37,660} \geq 1.91\right.$, all $\left.P \leq 0.001\right)$. The latter implies that the degree of genetic variation is not the same in both sexes (Fry, 1992). Consequently, the genetic correlations between males and females were less than unity, ranging from 0.69 to 0.87 for the variance component estimate $r_{\mathrm{g}(\mathrm{sex})}$, from 0.72 to 0.87 (jackknife SE range: 0.02-0.08) for the corresponding jackknife estimate $r_{\mathrm{j}(\mathrm{sex})}$, and from 0.52 to 0.77 (SE range: 0.11-0.15) for the family mean estimate $r_{\mathrm{m}(\mathrm{sex})}$ (Table 1). The estimates were congruent but the variance component estimate was consistently higher than the family mean estimate (Fry, 1992; Simons \& Roff, 1996). All estimates of $r_{\mathrm{m}(\mathrm{sex})}$ were greater than zero and less than unity (one-sample $t$-tests; $P<0.05)$. All estimates of $r_{\mathrm{g}(\mathrm{sex})}$ were also greater than zero at $P<0.001$ as judged by the appropriate $F$-test (Fry, 1992), and all estimates of $r_{\mathrm{g}(\mathrm{sex})}$ and $r_{\mathrm{j} \text { (sex) }}$ were less than unity at $P<0.001$ ( $t$-test using the jackknife SE). Bonferroni corrections are inappropriate because in the case of highly correlated traits it must be expected that either all correlations are unity, or none are (Simons \& Roff, 1996).

\section{Testing Cheverud's conjecture}

There were nine morphological and three life history traits for females, and 10 morphological traits for males. The male dataset was analysed with and without seta length, the latter case facilitating direct comparison of the results for the sexes. There were thus 45 pairs of (i.e. correlations among) morphological traits (M-M) for males. For the females, there were $36 \mathrm{M}-\mathrm{M}$ correlations, three correlations among life history traits $(\mathrm{L}-\mathrm{L})$, and 27 correlations between life history and morphological traits (M-L). The latter two sets were lumped.

Overall, genetic $\left(r_{\mathrm{g}}\right)$ and phenotypic correlations $\left(r_{\mathrm{p}}\right)$ corresponded very well (Fig. 1 and Table 2): the slope of the regression of genetic on phenotypic correlations only differed significantly from unity for the male $\mathrm{M}-\mathrm{M}$ dataset when seta length was 


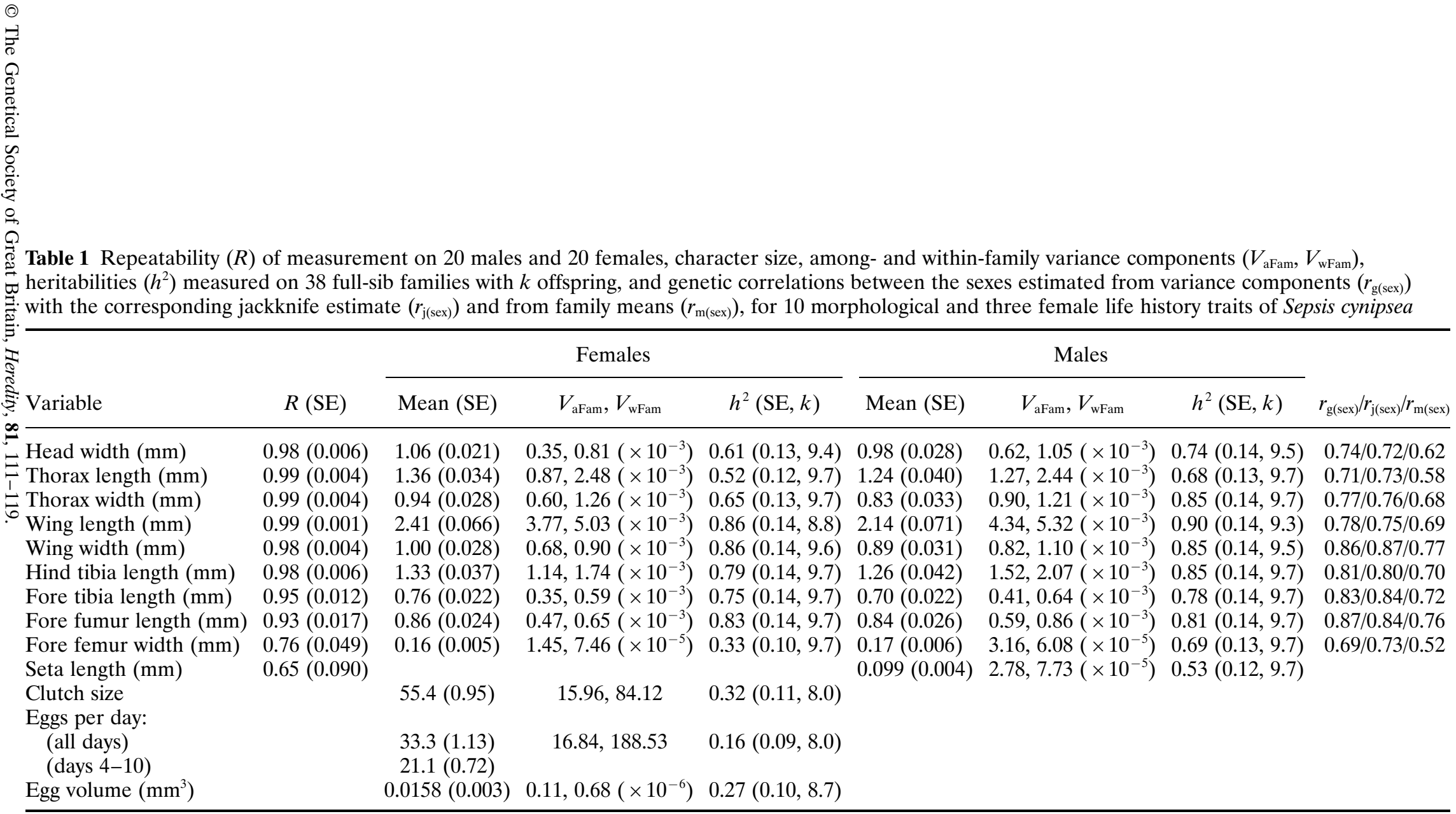

$k$, weighted mean family size (Becker, 1992; Roff, 1997). 


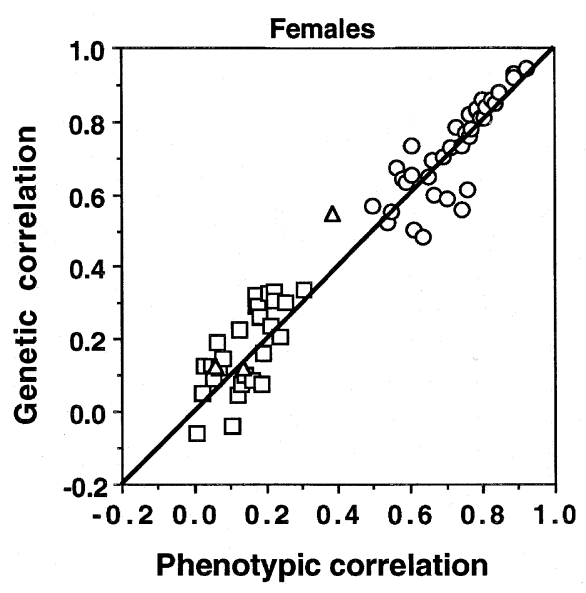

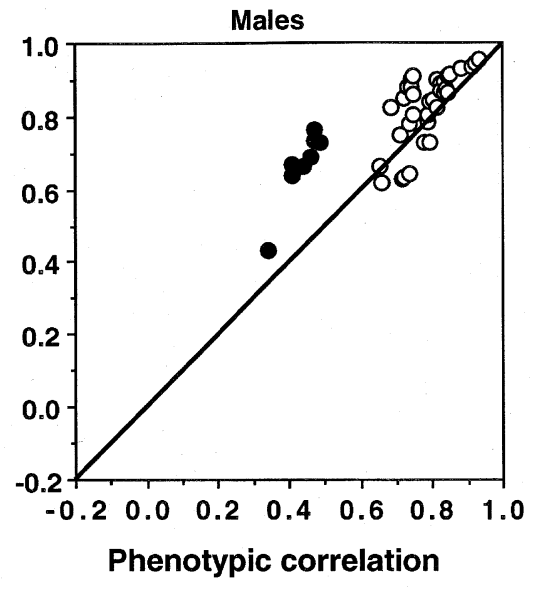

Fig. 1 Genetic vs. phenotypic correlations for female and male Sepsis cynipsea. The solid line shows the 1:1 relationship. For females three subsets of correlations are shown: combinations of morphological traits $\mathrm{M}-\mathrm{M}$ (circles), combinations between morphological and life history traits $\mathrm{M}-\mathrm{L}$ (squares), and combinations of life history traits $\mathrm{L}-\mathrm{L}$ (triangles). For males, filled circles denote the combinations involving seta length. included (Table 2). All except two genetic correlations were positive. The mean (range) $r_{\mathrm{g}}$ was 0.742 $(0.483,0.931)$ for female $\mathrm{M}-\mathrm{M}$ and $0.195(-0.057$, 0.548 ) for $\mathrm{M}-\mathrm{L}$ and $\mathrm{L}-\mathrm{L}$ trait combinations, and $0.810(0.432,0.956)$ for male $\mathrm{M}-\mathrm{M}$ combinations (Fig. 1). The corresponding mean (range) $\mathrm{SE}\left(r_{\mathrm{g}}\right)$ were $0.081(0.019,0.167)$ and $0.236(0.196,0.349)$ for females, and $0.057(0.014,0.145)$ for males. On average, genetic correlations involving life history traits had standard errors three times (and, in the extreme, one order of magnitude) greater than those involving morphological traits. Genetic correlations tended to be significantly greater than phenotypic correlations (i.e. above the diagonal; Fig. 1) for all subsets (binomial tests): 27 of 36 for female $\mathrm{M}-\mathrm{M}$ $(P=0.002), 20$ of 30 for female $\mathrm{M}-\mathrm{L}$ and $\mathrm{L}-\mathrm{L}$ $(P=0.049)$, and 38 of 45 for male $\mathrm{M}-\mathrm{M}(P<0.001)$.

Genetic correlations $r_{\mathrm{m}}$ based on the family mean method (Via, 1984) closely matched those based on the ANCOVA method $r_{\mathrm{g}}$ (Fig. 2 and Table 2). For the dataset reported here both methods were thus equally applicable (Roff, 1997).

Table 2 Parameters for (a) the regression of the genetic correlation on the phenotypic correlation, (b) the regression of the genetic correlation on the correlation of family means, and the mean absolute difference $D_{\text {abs }}$ between the two

\begin{tabular}{lllccc}
\hline Sex & Character combination $\dagger$ & Slope & Intercept & $r$ & $D_{\text {abs }}$ \\
\hline (a) & & & & & \\
Females & M-M & 0.99 & 0.01 & 0.84 & 0.052 \\
& M-L and L-L & 1.16 & 0.01 & 0.79 & 0.076 \\
& All & 0.96 & 0.04 & 0.97 & 0.063 \\
Males & M-M & $0.57^{*}$ & 0.39 & 0.76 & 0.100 \\
& M-M $\ddagger$ & 0.96 & 0.08 & 0.69 & 0.068 \\
(b) & & & & & \\
Females & M-M & 1.00 & 0 & 0.99 & 0.015 \\
& M-L and L-L & 0.84 & 0 & 0.83 & 0.056 \\
& All & 0.98 & 0 & 0.97 & 0.034 \\
Males & M-M & 1.05 & -0.04 & 1.0 & 0.008 \\
& M-M $\ddagger$ & 1.04 & -0.03 & 1.0 & 0.006 \\
\hline
\end{tabular}

$\dagger$ Character combinations as in Fig. 1.

†Seta length excluded.

*Significantly different from 1.0 at $P<0.05$ (Mantel text). 
Fig. 2 Genetic correlation as estimated from ANCOVAs vs. the genetic correlation as estimated from family means for female and male Sepsis cynipsea. The solid line shows the 1:1 relationship. Symbols are as in Fig. 1.

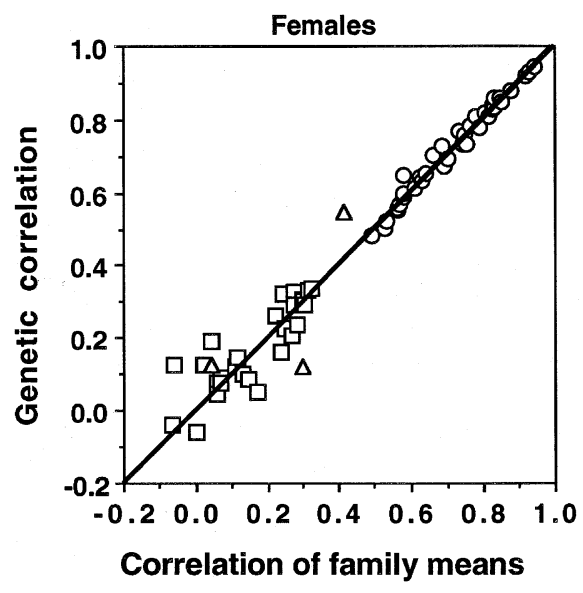

\section{Discussion}

Genetic variation and its consequences for morphological evolution

Heritabilities of most morphological traits in the dung fly $S$. cynipsea were quite high, higher than the average reported for ectotherms by Mousseau \& Roff (1987). In contrast, the heritabilities of female fecundity and egg size were, as expected, lower and comparable to those of other ectotherms (Mousseau \& Roff, 1987). As these estimates were derived from full-sib analyses, they probably overestimate the true heritabilities to some extent (see discussion below). Body size (i.e. head width, wing length or hind tibia length) and some male fore leg features are sexually selected in S. cynipsea (Ward, 1983; Allen \& Simmons, 1996; Blanckenhorn et al., 1998). Fecundity selection on body size is also strong (W. U. Blanckenhorn et al., unpubl. obs.). High heritabilities imply the potential for fast responses to selection on morphology in this species.

The genetic correlations in morphology between the sexes were also high. The higher this genetic correlation, the longer is the time required for sexual size dimorphism to evolve; in fact, this time will theoretically be infinite if the correlation is unity (Lande, 1980; Reeve \& Fairbairn, 1996). Our estimates $r_{\mathrm{m}(\mathrm{sex})}$ based on the Pearson product-moment correlation of family means were generally lower than those of $r_{\mathrm{g}(\mathrm{sex})}$ based on the ANCOVA method (Fry, 1992; Simons \& Roff, 1996; Roff, 1997). Both were significantly less than unity for all traits based on one-sample $t$-tests. A jackknife procedure was used to estimate the standard error of $r_{\mathrm{g}(\mathrm{sex})}$, as no statistical test is available (D. A. Roff, per. com.). These results must be considered preliminary, as Roff (1997, p. 42) cautions against indiscriminate use of jackknife procedures unless it is established that they are appropriate for the particular problem at hand (see also Roff \& Preziosi, 1994; Simons \& Roff, 1994, 1996). However, we have confidence in our results because of the good correspondence between the genetic correlations derived from the family mean and the ANCOVA methods (see below; Simons \& Roff, 1996; Roff, 1997).

Obviously, sexual size dimorphism has evolved in S. cynipsea. This would be greatly facilitated if genetic correlations in morphology between the sexes were indeed less than unity. Furthermore, faster responses to selection in one sex compared to the other would be possible if the amount of genetic variation differed between the sexes. Even though the heritabilities of all morphological traits were similar for males and females, the mean-standardized coefficients of genetic variation $C V_{\mathrm{aFam}}$, a measure closely related to 'evolvability' (Houle, 1992), were higher for males. However, the meanstandardized genetic and residual variability of all traits measured here (including egg size), except clutch size and eggs per day, and therefore the evolvability of these traits, is comparatively low (Houle, 1992).

\section{Correspondence of phenotypic and genetic correlations}

As with the majority of studies addressing this question to date (listed in the Introduction), this study of S. cynipsea revealed that, overall, phenotypic correlations $r_{\mathrm{p}}$ are good substitutes for genetic correlations $r_{\mathrm{g}}$, both for combinations of morphological traits (M-M) and for combinations of morphological and life history traits (M-L); the small number of correlations among female life history traits $(\mathrm{L}-\mathrm{L})$ does 
not permit any conclusions. However, the correspondence between $r_{\mathrm{g}}$ and $r_{\mathrm{p}}$ in males was strongly and uniquely reduced by the inclusion of seta length. As Roff (1995), we also found that $r_{\mathrm{g}}$ was generally greater than $r_{\mathrm{p}}$. This was disproportionately the case for the pairs of traits involving seta length (Fig. 1). We cannot offer an explanation for this phenomenon, but it suggests that general patterns may not hold for particular traits.

Our dataset further revealed that genetic correlations estimated from the ANCOVA $\left(r_{\mathrm{g}}\right)$ and the family mean $\left(r_{\mathrm{m}}\right)$ methods corresponded very well (Via, 1984; Roff, 1997). Roff \& Preziosi (1994) have shown that the family mean method can be substantially biased unless family size is large $(\geq 20)$. This does not seem to be the case here, even though family size was only about 10 .

All phenotypic and all but two genetic correlations among the traits measured were positive. This includes those between clutch size and egg volume $\left(r_{\mathrm{p}}=0.06\right.$ and $\left.r_{\mathrm{g}}=0.13\right)$ and between eggs per day and egg volume (all days: $r_{\mathrm{p}}=0.13$ and $r_{\mathrm{g}}=0.12$; days 4-10: $r_{\mathrm{p}}=0.10$ and $r_{\mathrm{g}}=0.14$ ), suggesting no strong trade-off between fecundity and egg size (Roff, 1992). The phenotypic correlation between development time and body size, estimated over a range of temperatures, is also low $\left(r_{\mathrm{p}}=0.08\right.$; Blanckenhorn, 1997).

The genetic correlations among morphological traits were very high, as were the corresponding heritabilities. This may relate to the relatively uniform environmental conditions in our laboratory experiment (Willis et al., 1991), as full-sib genetic estimates contain variance attributable to dominance and common environment (Falconer, 1989). However, we do not believe that our results are therefore strongly biased. First, laboratory and field estimates of heritabilities and genetic correlations are, in general, similar (Simons \& Roff, 1994, 1996; Weigensberg \& Roff, 1996). Secondly, full-sib genetic estimates of morphological (but only some behavioural and life history) traits in Drosophila and various animals are generally not higher than those derived from parent-offspring regression (Mousseau \& Roff, 1987; Roff \& Mousseau, 1987). This implies that nonadditive genetic effects of quantitative traits are typically small relative to sampling variance (see also Koots \& Gibson, 1996; Roff, 1997). Thirdly, we know from another laboratory experiment, where the clutch of a female was split into two containers, that container (i.e. common environment) effects on morphological traits are small (i.e. nonsignificant) compared to family and temperature effects and can therefore be neglected in this species, at least when employing our typical rearing methods as used here (W. U. Blanckenhorn, unpubl. obs.). All these arguments notwithstanding, it must be noted that full-sib studies like the one reported here will tend to bias results in favour of Cheverud's conjecture.

Overall, our population of $S$. cynipsea showed high levels of genetic variability, particularly in morphology. Differential selection on body size in males and females can thus be expected to produce rapid evolutionary responses in this species, possibly leading to further variation in sexual size dimorphism, as genetic correlations between the sexes were significantly less than unity (Fairbairn \& Preziosi, 1994; Reeve \& Fairbairn, 1996). Furthermore, Cheverud's (1988) conjecture also holds true in dung flies. Taken together, the majority of studies to date support the view that phenotypic correlations are, in most cases, good substitutes for genetic correlations (Roff \& Mousseau, 1987; Cheverud, 1988; Roff, 1995, 1996; Koots \& Gibson, 1996; Simons \& Roff, 1996; Tucic \& Avramov, 1996; Bonnin et al., 1997; this study; but see Hughes, 1995). This is good news for evolutionary ecologists, as it strengthens the view that evolutionary inferences can be drawn from phenotypic data without necessarily requiring laborious quantitative genetic estimates.

\section{Acknow ledgements}

We thank P. Ward and four anonymous referees for comments and D. Roff for much advice. This study was supported by grant no. 31-40496.94 from the Swiss National Fund.

\section{References}

Allen, G. R. AND SIMmONS, L. W. 1996. Coercive mating, fluctuating asymmetry and male mating success in the dung fly Sepsis cynipsea. Anim. Behav., 52, 737-741.

ARNOLD, S. J. AND WADE, M. J. 1984. On the measurement of natural and sexual selection: theory and applications. Evolution, 38, 709-734.

BECKER, w. A. 1992. Manual of Quantitative Genetics, 5th edn. Students Book Corporation, Pullman, WA.

BLANCKENHORN, w. U. 1997. Altitudinal life history variation in the dung flies Scathophaga stercoraria and Sepsis cynipsea. Oecologia, 109, 342-352.

BLANCKENHORN, W. U., REUSCH, T. AND MÜHLHÄUSER, C. 1998. Fluctuating asymmetry, body size and sexual selection in the dung fly Sepsis cynipsea-testing the good genes assumptions and predictions. J. Evol. Biol., 11, (in press).

BONNIN, I., PROSPERI, J. M. AND OLIVIERI, I. 1997. Comparison of quantitative genetic parameters between two natural populations of a selfing plant species, Medicago truncatula. Theor. Appl. Genet., 94, 641-651. 
CHEVERUD, J. M. 1988. A comparison of genetic and phenotypic correlations. Evolution, 42, 958-968.

FAIRBAIRN, D. J. AND PREZIOSI, R. F. 1994. Sexual selection and the evolution of allometry for sexual size dimorphism. Am. Nat., 144, 101-118.

FALCONER, D. S. 1989. Introduction to Quantitative Genetics, 3rd edn. Longman, Harlow.

FRY, J. D. 1992. The mixed-model analysis of variance applied to quantitative genetics: biological meaning of the parameters. Evolution, 46, 540-550.

HOULE, D. 1992. Comparing evolvability and variability of quantitative traits. Genetics, 130, 195-204.

Hughes, K. A. 1995. The evolutionary genetics of male life-history characters in Drosophila melanogaster. Evolution, 49, 521-537.

JABLONSKI, D. 1997. Body-size evolution in Cretaceous molluscs and the status of Cope's rule. Nature, 385, $250-252$.

KOOTS, K. R. AND GIBSON, J. P. 1996. Realized sampling variances of estimates of genetic parameters and the difference between genetic and phenotypic correlations. Genetics, 143, 1409-1416.

LANDE, R. 1980. Sexual dimorphism, sexual selection, and adaptation in phylogenetic characters. Evolution, 34, 292-307.

LANDE, R. AND ARNOLD, S. J. 1983. The measurement of selection on correlated characters. Evolution, 37, 1210-1226.

MEIER, R. 1996. Larval morphology of the Sepsidae (Diptera: Sciomyzoidea), with a cladistic analysis using adult and larval characters. Bull. Am. Mus. Nat. Hist., 228, 1-147.

MOUSSEAU, T. A. AND ROFF, D. A. 1987. Natural selection and the heritability of fitness components. Heredity, 59, 181-198.

PETERS, R. H. 1983. The Ecological Implications of Body Size. Cambridge University Press, Cambridge.

PONT, A. C. 1979. Sepsidae. Diptera, Cyclorrhapha, Acalyptrata. In: Fitton, M. G. (ed.) Handbook for the Identification of British Insects, vol. X, part, 5, pp. 1-35. Royal Entomological Society, London.

REEVE, J. P. AND FAIRBAIRN, D. J. 1996. Sexual size dimorphism as a correlated response to selection on body size: an empirical test of the quantitative genetic model. Evolution, 50, 1927-1938.

ROFF, D. A. 1992. The Evolution of Life Histories: Theory and Analysis. Chapman \& Hall, London.

ROFF, D. A. 1995. The estimation of genetic correlations from phenotypic correlations: a test of Cheverud's conjecture. Heredity, 74, 481-490.

ROFF, D. A. 1996. The evolution of genetic correlations: an analysis of patterns. Evolution, 50, 1392-1403.

ROFF, D. A. 1997. Evolutionary Quantitative Genetics. Chapman \& Hall, New York.

ROFF, D. A. AND MOUSSEAU, T. A. 1987. Quantitative genetics and fitness: lessons from Drosophila. Heredity, 58, 103-118.

ROFF, D. A. AND PREZIOSI, R. 1994. The estimation of the genetic correlation: the use of the jackknife. Heredity, 73, 544-548.

SCHMidt-nielsen, K. 1984. Scaling. Why is Animal Size so Important? Cambridge University Press, Cambridge.

SIMONS, A. AND ROFF, D. A. 1994. The effect of environmental variability on the heritabilities of traits of a field cricket. Evolution, 48, 1637-1649.

SIMONS, A. AND ROFF, D. A. 1996. The effect of a variable environment on the genetic correlation structure in a field cricket. Evolution, 50, 267-275.

TUCIC, B. AND AVRAMOV, s. 1996. Morphological integration in the seedlings of Iris pumila. Genetika, 32, 1235-1242.

VIA, s. 1984. The quantitative genetics of polyphagy in an insect herbivore. II. Genetic correlations in larval performance within and among host plants. Evolution, 38, 896-905.

WARD, P. I. 1983. The effects of size on the mating behaviour of the dung fly Sepsis cynipsea. Behav. Ecol. Sociobiol., 13, 75-80.

WEIGENSBERG, I. AND ROFF, D. A. 1996. Natural heritabilities: can they be reliably estimated in the laboratory? Evolution, 50, 2149-2157.

Willis, J. H., COYNe, J. A. AND KiRkPATRICK, M. 1991. Can one predict the evolution of quantitative characters without genetics? Evolution, 45, 441-444.

YAMADA, Y. 1962. Genotype by environment interaction and genetic correlation of the same trait under different environments. Jap. J. Genet., 37, 498-509. 